\title{
Los problemas de lenguaje entre los universitarios
}

Sin padecer del complejo de analista político, enfermedad tan generalizada en nuestro medio, en razón de que la política coyuntural la han descendido a niveles insoportables, insufribles e intrascendentes, me parece que resulta más útil dedicar nuestro tiempo a ocuparnos de otros temas o problemas con mayor trascendencia práctica para nuestra sociedad; así, por ejemplo, en esta ocasión quiero llamar la atención sobre la problemática del lenguaje.

Ciertamente, nunca me he dedicado a tareas docentes vinculadas con el lenguaje, ya se trate del oral o del escrito y, por ello, los problemas que he podido observar desde mi óptica de no especialista me resultan escandalosamente dramáticos. Insisto, no se trata de los juicios de un experto, escandalizado por errores detectables, incluso, en este mi escrito y por tal razón mis observaciones, me parece que revelan la existencia de un problema serio en el ambiente universitario, el cual podría generalizarse al ámbito nacional, en términos de comunicación oral y escrita.

Mi opinión es que, sin lugar a dudas, el lenguaje de la mayoría de jóvenes se está empobreciendo y parece que nadie se ha percatado de las implicaciones terribles que ello puede tener, en la formación de buenos profesionales. ¿Cómo podrán asimilar los contenidos, si no entienden las palabras en que se expresan los mismos? ¿Cómo podrán expresar contenidos si no conocen el lenguaje? $\mathrm{Y}$ no me refiero a problemas relacionados con la ortografía y la redacción, los cuales son males crónicos señalados desde siempre en las reuniones de profesores. Por eso se imparten algunos cursos de redacción. Me refiero a algo mucho más elemental o primario, como es el no conocer el significado de las palabras, lo cual imposibilita la comunicación.

Tan sólo como una muestra mínima de lo que estoy tratando de exponer, presento una lista de palabras que les resultaron inintelegibles a algunos estudiantes durante el último ciclo lectivo y, que conste, se trataba en su gran mayoría de estudiantes de último año. Estas son algunas de esas palabras "incomprensibles": alternativo, abismal, reformule, universalizable, heterogénea, eufemismo, inequivoco, etc. Son palabras sencillas, comunes y corrientes; sin embargo, muchos estudiantes universitarios de años superiores, sencillamente, no conocen ni siquiera vagamente su significado, lo cual dificulta seriamente la comunicación profesor-alumno. Generalmente, en los exámenes tal pobreza en el lenguaje se hace evidente y convierte las preguntas más sencillas en verdaderos arcanos.

Por otra parte, nunca olvido el caso de un estudiante que, en su trabajo de graduación, escribía "sean" y como el párrafo donde lo usaba me resultaba sin sentido, terminé por preguntarle qué era lo que quería decir, y en su lenguaje oral entendí que lo que quería expresar era: "se han". Pero, en la actualidad, no me quiero referir a ese tipo de problemas, no obstante que siguen estando presentes.

En el trabajo universitario, las anécdotas son muy abundantes y acudiré a las mismas para tratar el problema del cual me ocupo. El problema no es nuevo, lo vengo observando desde hace varios 


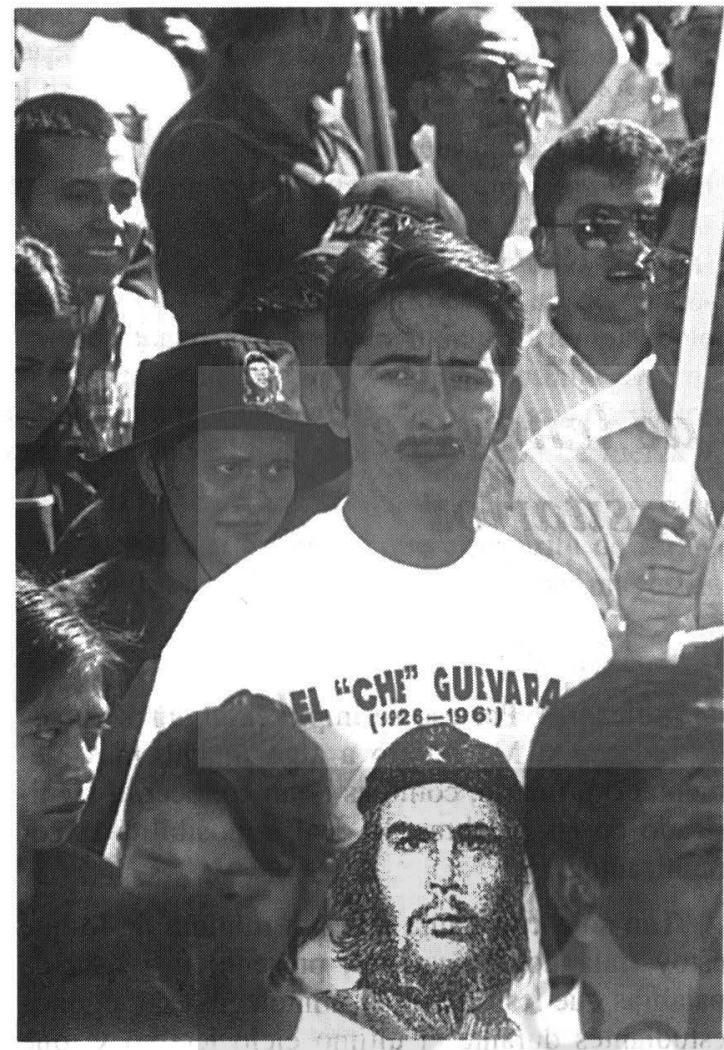

años atrás. Cierto día en que pregunté en un aula si sabían el significado de la palabra heterogéneo y comprobando que nadie lo conocía, les manifesté si conocían el de homogéneo, a lo cual respondieron que sí. Entonces les manifesté que heterogéneo era lo contrario a homogéneo. Observando que ambas palabras se diferencian en el prefijo. En un caso heteros: otro, diferente; y homos: igual, semejante. Les pregunté, entonces, que si en sus estudios de secundaria les enseñaban aún las raíces griegas y latinas. Alguien dijo: ¿qué cosa es eso?, como muestra de que no tenían ni idea de lo que estaba hablando. De conocerlas, fácilmente hubieran podido deducir el significado de la palabra heterogéneo, ya que conocían el de homogéneo.

Les preguntaba lo anterior porque, cuarenta años atrás, yo las estudié y, ciertamente, me han sido muy útiles para ampliar mi patrimonio lingüístico. Aunque lo anterior no es una justificación válida, ya que si revisamos el diccionario, aunque sea el Pequeño Larousse, encontraremos que en el mismo se señala que heteros y homos son raíces griegas y que si se asimilan, no habrá mayor problema en comprender que helerodoxia hace referencia a algo diferente, y si adicionalmente se conoce que doxia significa opinión, pues fácilmente se entenderá que los heterodoxos en política son aquellos que tienen opiniones diferentes, i.e. que no siguen la ortodoxia, lo cual nos llevaría a la necesidad de conocer la raíz griega: orthos. Pero bien, esto cabe en el ámbito de las posibles soluciones que se pueden ofrecer para que quien quiera enriquecer su lenguaje lo haga. A los políticos que tanto hablan en público bueno les haría enriquecer su lenguaje y con ello no sólo se harían un gran favor a sí mismos, sino que prestarían, al menos, ese servicio a la comunidad. Valga el paréntesis.

Se ha realizado una reforma en educación. No sé si sus ilustres mentores, entre quienes se cuentan algunos ex profesores de nuestra querida casa de estudios, se han ocupado de buscar enriquecer el léxico de los estudiantes. Pero para ello tendrían que haberse enterado de que existe tal problema, porque de muy poco sirve reformar los contenidos programáticos si el vehículo para acceder a los mismos no funciona o si quienes enseñan sufren también de pobreza en el lenguaje. Me pregunto: ¿realmente se habrán enterado las autoridades de educación de que el lenguaje de los jóvenes se está empobreciendo?

Pienso que luego de varias generaciones de "hijos de la televisión", lo anterior es simple de comprender. El lenguaje de la tele es pobrísimo, ya se trate de películas, de programas en vivo o los mismos noticieros, en los cuales los presentadores, o mejor dicho los preguntadores, en su gran mayoría, padecen el mal del cual nos ocupamos. Y por otra parte, si el hogar, que es el lugar donde nuestros hijos aprenden, primaria y fundamentalmente el idioma, maneja un lenguaje muy pobre y simplificado, donde la gran mayoría de expresiones que se usan no son más que "malas palabras", como mierda, puta, cabrón, jodido, pendejo, pijudo, vergón, cachimbón, super, etc. En vez de usar los calificativos precisos, por ejemplo, comida desabrida, dicen comida mierda; vecina puta por vecina bulliciosa o escandalosa; niño jodido por niño inquieto o molesto; padre cabrón por padre irresponsable; muchacho pendejo por muchacho despreocupado o irresponsable; trabajo pijudo por trabajo brillante, original; estudiante cachimbón por estudiante dedicado, estudioso, diligente, etc. $\mathrm{O}$ bien, que todo se reduce a un mismo calificativo: comida mierda, vecina mierda, camisa mierda, 
estudiante mierda, padre mierda, trabajo mierda, bus mierda, casa mierda, calle mierda, etc. Siendo éstas las prácticas habituales en muchos hogares, resulta comprensible que los muchachos usen tal lenguaje con sus amigos, pero que teman sobremanera hablar en clase, y cuando lo hacen, les resulta una cosa terrible y complicada, que les exige realizar grandes esfuerzos para encontrar las palabras apropiadas, cuando las encuentran; no obstante, en los corrillos no paran de hablar. Pero si nos diéramos a la tarea de contarles cuántas veces han dicho las palabras: puta y super en una conversación de diez minutos, nos quedaríamos asombrados.

En muchas disciplinas particulares que se cursan en la universidad, ciertamente, aparece una cantidad de palabras muy propias de la especialidad, lo que les viene a dificultar aún más las cosas a los estudiantes, quienes, en más de alguna ocasión, me han pedido que se les facilite un glosario; sin embargo, si se tuviera una base sólida del lenguaje, los términos nuevos se asimilarían fácilmente dentro del contexto en que se usan y conforme a las explicaciones propias de cada saber particular, impartidas por el profesor respectivo, ya se trate de filosofía, de sociología o de economía, ámbitos dentro de los cuales nos movemos los profesionales de las ciencias económicas, ya se trate de economistas, administradores de empresas o de contaduría. Prefiero no referime a los estudiantes de ingeniería o de ciencias humanas, con quienes nunca he tenido el placer de compartir conocimientos. No obstante, creo que experimentan los mismos o semejantes problemas en materia de lenguaje, dado que este problema, como muchos otros que padecemos en nuestro país, tiene orígenes estructurales.

Pienso que, como en todo, existen excepciones. En este caso, gratas excepciones de estudiantes que se expresan muy bien, que escriben de manera excelente y que, incluso, su letra es tan clara que da gusto calificar sus exámenes. Pero la generalidad es lo contrario.

¿Qué se puede hacer para revertir esta tendencia? Al menos, en los centros educativos, porque si los padres tienen un lenguaje empobrecido es muy poco lo que pueden aportar, pero si no es el caso, sería recomendable que les hablaran a sus hijos usando correctamente el lenguaje, el cual además de vastísimo es muy bello.

En los centros educativos básicos se debería de estimular la lectura, el uso del diccionario y el conocimiento de las raíces griegas y latinas. La lec- tura, a diferencia de la televisión, no sólo permite enriquecer el lenguaje, sino que a su vez estimula y desarrolla la imaginación, lo cual es clave para lograr habilidades creativas. La televisión no deja lugar a la imaginación ni a la creatividad, fruto de la misma es que el estudiante antes que usar su imaginación, su creatividad, quiere que se le dé todo resuelto, encapsulado, meras recetas, como si la realidad en su hermosa complejidad admitiera las recetas. Es obvio que con actitudes poco imaginativas y creativas a muchos profesionales les hayan resultado tan atractivas las recetas del Banco Mundial y del Fondo Monetario Internacional, las cuales, afortunadamente, bastante pronto han demostrado que sirven para muy poco.

Los profesores universitarios, aquellos que creemos que esta actividad vale la pena el esfuerzo y que nos sentimos maestros más que transmisores autómatas de conocimientos o de teorías, podríamos contribuir de muchas maneras, aunque no con las prácticas represivas de bajar puntos por ortografía, sino más bien estimulando al conocimiento del lenguaje, usando en el aula muchos sinónimos, destacando y explicando ciertas palabras que son claves para la comprensión de determinados contenidos. Solicitando trabajos de lecturas complementarias, de las cuales los estudiantes saquen todas las palabras que no les resulten comprensibles y las busquen en diccionarios o las consulten con otros profesores, etc.

Adicionalmente, a mí me ayuda mucho para enriquecer el lenguaje poner mucha atención al léxico de los campesinos, a las personas originarias del interior de la república y últimamente, a los programas de opinión de la televisión española. También no tener ningún reparo en consultar a compañeros o amigos sobre algunos neologismos, que no es posible encontrar en los diccionarios. Recientemente anduve interrogando sobre lo que significa multimedia. Claro, no es recomendable conformarse con la primera opinión, ya que puede resultar equivocada.

Finalmente, tomar conciencia de que si no enriquecemos nuestro lenguaje personal nos estamos negando la posibilidad para aprender, para conocer muchísimas cosas interesantes. Pensar que no es que al profesor no se le entiende, sino que no lo entendemos dado nuestro reducido vocabulario o que si entendemos mal los contenidos no es porque seamos tontos, sino porque no contamos con el dominio suficiente del lenguaje. 
Mucho ganaríamos, en términos de superación individual y social, si enriquecemos nuestro lenguaje. No creo que esté demás aprender inglés, pero de muy poco servirá si no se conoce bien el lenguaje matemo. Muchas de las películas dobladas al español adolecen del serio problema de que quienes las doblan no conocen suficientemente el idioma.
Bien, antes que hablar de política, mejor hablemos de nuestra propia lengua, la cual estamos empobreciendo, reduciéndola a unos niveles críticos y con ello reduciendo nuestros niveles de pensamiento, de formación profesional, de creatividad y de formulación de ideas.

\section{Aquiles Montoya}

